\title{
Protein Kinase Inhibitors Selectively Block Phorbol Ester- or Forskolin-Induced Changes in Excitability of Aplysia Neurons
}

\author{
P. Jeffrey Conn, ${ }^{1, a}$ Judith A. Strong, ${ }^{1, b}$ Edward M. Azhderian, ${ }^{1}$ Angus C. Nairn, ${ }^{3}$ Paul Greengard, ${ }^{3}$ and Leonard \\ K. Kaczmarek ${ }^{1,2}$ \\ Departments of 'Pharmacology and 'Physiology, Yale University School of Medicine, New Haven, Connecticut 06510, and \\ ${ }^{3}$ Laboratory of Molecular and Cellular Neuroscience, Rockefeller University, New York, New York 10021
}

\begin{abstract}
Exposure of the bag cell neurons of Aplysia to activators of protein kinase $\mathbf{C}$, such as phorbol esters, enhances electrically evoked action potentials by increasing the voltagedependent calcium current. We have hypothesized that this effect is mediated by the activation of protein kinase $C$ (PKC). An important prediction of this hypothesis is that inhibitors of PKC should inhibit these phorbol ester-induced changes in bag cell neuronal excitability. We have now found that treatment of bag cell neurons with the protein kinase inhibitor 1-[5-isoquinolinesulfonyl]-2-methyl piperazine $(H-7)$ inhibits the phorbol ester-induced enhancement of bag cell action potentials and prevents the enhancement of calcium current by phorbol esters. The height and width of electrically evoked action potentials in bag cell neurons can also be enhanced by CAMP analogs or agents that elevate CAMP. These agents do not influence the major voltage-dependent calcium current in the bag cell neurons but may act by modulating potassium currents and other voltage-dependent currents. We have found that microinjection of a protein inhibitor of CAMP-PK (PKA-I) into isolated bag cell neurons prevents and reverses the effect of the adenylate cyclase activator forskolin on action potentials of these cells. In contrast, $\mathrm{H}-7$ does not inhibit the effects of forskolin on a variety of responses in these cells, including its effects on action potentials, granule movement, and ${ }^{32} \mathrm{P}$ incorporation into phosphoproteins. This suggests that $\mathrm{H-7}$ is selective for PKC relative to CAMP-PK in intact bag cell neurons.
\end{abstract}

Activation of specific protein kinases is a common mechanism by which second messengers mediate their effects on cell function. Specificity of action of different second messengers in a given cell can be conferred by activation of different classes of protein kinases, which, in turn, phosphorylate a variety of cellspecific protein substrates (Nestler and Greengard, 1984). Thus, adenosine-3',5'-monophosphate (cAMP) activates cAMP-dependent protein kinase (cAMP-PK), whereas the phosphoino-

\footnotetext{
Received Nov. 27, 1987; revised June 24, 1988; accepted June 27, 1988 .

This work was supported by grants NS-18492 to L.K.K., PHS fellowships NS07136-08 and NF-08228-01 to P.J.C., and NS-21550 to P.G.

Correspondence should be addressed to Dr. Leonard K. Kaczmarek, Department of Pharmacology, Yale University School of Medicine, 333 Cedar Street, New Haven, CT 06510 .

a Present address: Department of Pharmacology, Emory University School of Medicine, Atlanta, GA 30322.

b Present address: Department of Biological Sciences, Purdue University, West Lafayette, IN 47907.

Copyright (C) 1989 Society for Neuroscience $0270-6474 / 89 / 020473-07 \$ 02.00 / 0$
}

sitide hydrolysis-derived second messenger diacylglycerol (DAG) activates protein kinase $\mathrm{C}$ (PKC) and calcium activates calcium/ calmodulin-dependent protein kinases $\left(\mathrm{Ca}^{2+} / \mathrm{CaM}-\mathrm{PK}\right)$ and PKC.

The bag cell neurons of Aplysia have been used to investigate the role of protein kinases in the control of neuronal excitability (Kaczmarek et al., 1986). Brief stimulation of an afferent input into these cells increases both cAMP levels and phosphoinositide hydrolysis and induces a prolonged transition in the electrical properties of the cells from an inexcitable state (in which no spontaneous action potentials occur) to a highly excitable state in which repetitive fring occurs and action potentials are enhanced. This repetitive firing results in release of neuropeptides that initiate egg-laying behavior in Aplysia.

Intracellular injection of $\mathrm{PKC}$, or treatment with activators of this enzyme, enhances action potentials in isolated bag cell neurons (DeReimer et al., 1985). This effect of PKC results from the unmasking of a normally covert large conductance voltagedependent calcium channel (Strong et al., 1987). Activators of $\mathrm{PKC}$ are without direct effect on voltage-dependent potassium currents in these neurons.

Injection of the catalytic subunit of cAMP-PK, treatment with cAMP analogs or with the adenylate cyclase activator forskolin or application of a peptide that elevates cAMP levels, also enhances the amplitude and duration of evoked action potentials (Kaczmarek et al., 1980; Kaczmarek and Strumwasser, 1981; Kauer and Kaczmarek, 1985; Loechner and Kaczmarek, 1987). In addition, application of cAMP analogs or forskolin can trigger an afterdischarge in bag cell clusters and isolated cells (Kaczmarek and Strumwasser, 1981; Kauer and Kaczmarek, 1985). Voltage-clamp experiments indicate that the cAMP analogs and forskolin decrease voltage-dependent potassium currents without affecting the major voltage-dependent calcium current in these cells (Kaczmarek and Strumwasser, 1984; Strong, 1984; Strong and Kaczmarek, 1986, 1987). However, voltage-clamp experiments have not been carried out for cAMP-PK catalytic subunit-injected cells.

The above experiments provide evidence that the effects of cAMP and phorbol esters are mediated by activation of cAMP$\mathrm{PK}$ and PKC, respectively, and that these kinases contribute to the transition of the electrical properties of bag cell neurons that occurs with increases in cAMP levels and phosphoinositide hydrolysis in the intact abdominal ganglion. A prediction of this hypothesis is that inhibitors of CAMP-PK and PKC should inhibit the effects of cAMP and phorbol esters, respectively, and that such agents should influence the properties of the afterdischarge in intact clusters. In general, investigation of the relative 
roles of the various protein kinases in modulating cell function has suffered from a lack of selective inhibitors of the different protein kinases. However, an endogenous, specific protein inhibitor of CAMP-PK (PKA-I) has been useful in establishing a role for CAMP-PK in certain CAMP-mediated processes (Ashby and Walsh, 1972; Adams and Levitan, 1982; Castelluci et al., 1982). More recently, Hidaka et al. (1984) synthesized a protein kinase inhibitor called H-7 (1-[5-isoquinolinesulfonyl]-2-methyl piperazine). $\mathrm{H}-7$ potently inhibits $\mathrm{PKC}$ in vitro and is selective for this enzyme relative to $\mathrm{Ca} / \mathrm{CaM}-\mathrm{PK}$. The effect of $\mathrm{H}-7$ on $\mathrm{PKC}$ is maintained in intact cells, as is its selectivity for PKC over Ca/CaM-PK (Inagaki et al., 1984; Kawamoto and Hidaka, 1984; Fujita et al., 1986; Nishikawa et al., 1986; Shibanuma et al., 1987). Although H-7 can be bath-applied to intact cells and is widely used for studying PKC-mediated changes in cell function, this agent also inhibits cAMP-PK in cell-free extracts (Hidaka et al., 1984). In the present studies, we have investigated the effects of H-7 and PKA-I on the phorbol ester-, forskolinand cAMP-induced enhancement of action potentials in bag cell neurons. Some of the data reported here have been previously reported in abstract form (Conn et al., 1987, 1988; Kaczmarek et al., 1984).

\section{Materials and Methods}

Animals and cell culture. Aplysia californica $(150-400 \mathrm{gm})$ were obtained from Alacrity Marine Services (Redondo Beach, CA) and kept at $14^{\circ} \mathrm{C}$. The methods for cell culture were as described by Kaczmarek and Strumwasser (1981). The abdominal ganglion was removed and incubated in artificial seawater (ASW) with modified Eagle's medium (ASWMEM) at room temperature for $18 \mathrm{hr}$ in $1.25-2.0 \%$ neutral protease. The bag cell cluster was then dissectcd away from the rest of the ganglion and from the surrounding connective tissue and triturated into $35 \mathrm{~mm}$ plastic culture dishes (Corning) containing ASW-MEM. The cells were kept at $14^{\circ} \mathrm{C}$, and experiments were performed at room temperature $\left(22-25^{\circ} \mathrm{C}\right.$ ). ASW had the following composition (in $\mathrm{mm}$ ): $\mathrm{NaCl}, 460$; $\mathrm{KCl}, 10.4 ; \mathrm{HEPES}, 15 ; \mathrm{CaCl}_{2}, 11 ; \mathrm{MgCl}_{2}, 27 ; \mathrm{MgSO}_{4}, 28$; and glucose, 5.5 (pH 7.8). The culture medium (ASW-MEM) was made by adding essential and nonessential amino acids, vitamins, glutamine, penicillin, and streptomycin (Gibco) to the ASW (Kaczmarek and Strumwasser, 1981).

Intracellular injection of protein inhibitor of $C A M P-P K$. Intracellular recording microelectrodes were filled at the tip with $3.6 \mathrm{mg} / \mathrm{ml}$ of PKA-I prepared from rabbit skeletal muscle (Ashby and Walsh, 1972; Castelluci et al., 1982) in a carrier solution $(0.6 \mathrm{M} \mathrm{KCl}, 1 \mathrm{~mm}$ Tris $\mathrm{HCl}, \mathrm{pH}$ 7.8). Isolated bag cell neurons maintaincd in cell culture were injected with the inhibitor or with the carrier medium alone by applying pressure pulses (10-50 psi for $1-4 \mathrm{~min})$ to the inside of the microelectrodes $(\sim 20$ $\mathrm{M} \Omega$ ).

Measurement of action potentials in cultured bag cell neurons. Cultured bag cell neurons were impaled with a single high-resistance microelectrode (30-80 M $\Omega$ ) connected to a bridge circuit for current injection. Action potentials were elicited by injecting depolarizing current (0.1-2 nA), and data were recorded with either a Nicolet digital oscilloscope or an LSI 11/23 laboratory computer. The microelectrode was filled with $3 \mathrm{M} \mathrm{KCl}$.

Whole-cell voltage-clamp in cultured bag cell neurons. A whole-cell patch-clamp technique (Hamill et al., 1981) modified for use in larger cells (Strong, 1984) was used. For measurement of calcium currents the internal solution used in the dialysis pipette contained (in mM) TEAaspartate, 100; Cs-aspartate, 470; HEPES, 30; $\mathrm{MgCl}_{2}, 5 ; \mathrm{Na}_{2} \mathrm{ATP}, 5$; EGTA, 20; $\mathrm{CaCl}_{2}, 4.14$ and glucose, 5.5 (pH 7.3).

Measurement of organelle movement in growth cones of cultured bag cell neurons. For experiments involving use of video-enhanced light microscopy, 2-cm-diameter holes were cut into the bottom of $35 \mathrm{~mm}$ culture dishes and covered with $22 \times 22 \mathrm{~mm} \# 1$ glass coverslips coated with high-molecular-weight $(>300,000)$ poly-D-lysine (Sigma). A seal was formed between the coverslip and the culture dish with Dow Corning high-vacuum silicone grease. Cells were seeded onto the glass coverslips in L-15 medium (Leibovitz, 1963) supplemented with seawater salts as above and $50 \mu \mathrm{g} / \mathrm{ml}$ gentamycin sulfate (L-15 ASW) and maintained at $14^{\circ} \mathrm{C}$ until use.

Light microscopy was performed at room temperature in ASW using a Nikon Diaphot inverted bench microscope equipped with differential interference contrast optics and a Nikon planapo $60 / 1.4$ oil objective. An RCA video camera was used for obtaining video images, which were recorded on video tape.

The area of the growth cone that was filled with organelles was determined before addition of forskolin/theophylline $(50 \mu \mathrm{M} / 1 \mathrm{~mm})$ and 15-30 min after addition of forskolin/theophylline as described by Forscher et al. (1987). H-7 (100 $\mu \mathrm{M})$ was then added to the medium in the continued presence of forskolin/theophylline and the area of the growth cone filled with organelles was again measured 45 min after addition of $\mathrm{H}-7$ to see if $\mathrm{H}-7$ reverses the forskolin/theophylline effect. This allowed the use of each cell as its own control. Since removal of activators of cAMP-PK rapidly reverses the effect of these agents on organelle movement, it is expected that inhibition of cAMP-PK would reverse the effect of cAMP on organelle transport as well.

Measurement of forskolin-induced protein phosphorylation in cultured bag cell neurons. Bag cell neurons were incubated in $2 \mathrm{ml}$ of MEMASW for $6 \mathrm{hr}$ at $15^{\circ} \mathrm{C}$ prior to addition of $2 \mathrm{mCi}{ }^{32} \mathrm{P}$-orthophosphate

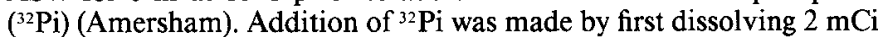
dried ${ }^{32} \mathrm{Pi}$ in $250 \mu \mathrm{l} \mathrm{MEM}-\mathrm{ASW}$ and then gently introducing the radioactive solution to the culture dish. Cells were incubated in this medium for approximately $12 \mathrm{hr}$ at $15^{\circ} \mathrm{C}$, after which each culture dish was immersed in $200 \mathrm{ml} \mathrm{ASW}$ (room temperature). Two $\mathrm{ml}$ of ASW was left in each dish, and appropriate drugs were added in $250 \mu \mathrm{l}$ ASW. Cells were incubated with or without forskolin/theophylline and/or H-7 for $55 \mathrm{~min}$ at room temperature. (Final drug concentrations were 50 $\mu \mathrm{M}$ forskolin, $1 \mathrm{~mm}$ theophylline, and $100 \mu_{\mathrm{M} \mathrm{H}} \mathrm{H}$.) The medium was then removed by aspiration, and $300 \mu$ lof a solution containing $1 \%$ SDS, $50 \mathrm{~mm}$ Tris, $5 \mathrm{~mm}$ EDTA, and $1 \mathrm{~mm}$ EGTA (pH 7.4; kept on boiling water) was added. The resultant extract was transferred to polypropylene tubes, heated in a boiling water bath, frozen on dry ice, and stored at $-70^{\circ} \mathrm{C}$ until later analysis.

Radiolabeled phosphoproteins in the extracts were resolved with 2-dimensional polyacrylamide gel electrophoresis (PAGE) according to the method of O'Farrell (1975) with the following modifications. Two hundred thousand cpm of radioactivity (determined by TCA precipitation) were adjusted to $200 \mu \mathrm{l}$ in the same solution as that used for extraction of phosphoproteins. The samples were lyophilized and dissolved in $125 \mu \mathrm{l}$ lysis buffer containing $9.5 \mathrm{~m}$ urea, $2 \% \mathrm{pH} \mathrm{5-7} \mathrm{am-}$ pholytes (LKB), 5\% 2-mercaptoethanol, and $8 \%$ Nonindet P-40. The first-dimension gel was the same as that of O'Farrell (1975), except that it contained 4 parts pH 4-6 ampholytes and 1 part $\mathrm{pH}$ 3.5-10 ampholytes. Proteins were loaded onto nonprefocused gels, and the first dimension was run for $14,000 \mathrm{~V} \mathrm{hr}$. The second dimension was identical to that described by O'Farrell (1975). Dried gels were exposed to Kodak XRP-1 film with a Dupont Cronex intensifying screen.

Chemicals. Forskolin (Calbiochem) was kept at $4^{\circ} \mathrm{C}$ as a $10 \mathrm{~mm}$ stock solution in ethanol. H-7 was obtained from Seikagaku America Inc. (St. Petersburg, FL) and kept at $4^{\circ} \mathrm{C}$ as a $10 \mathrm{~mm}$ stock solution in water. TPA (12-O-tetradecanoyl-13-phorbol acetate) was kept frozen at $-20^{\circ} \mathrm{C}$ as a $1 \mathrm{~mm}$ stock solution in dimethyl sulfoxide. Theophylline stock solutions were $10 \mathrm{~mm}$ in ASW. Dilutions of these agents were made to the appropriate concentrations in ASW.

\section{Results}

Effect of $\mathrm{H}-7$ on phorbol ester-induced enhancement of action potentials and calcium currents

Application of the phorbol ester TPA to isolated bag cell neurons enhances action potential height by increasing voltage-dependent calcium current. The pharmacology of this response is consistent with its mediation by $\mathrm{PKC}$, and the response can be mimicked by intracellular injection of the enzyme (DeReimer et al., 1985; Strong et al., 1987). In the present studies, we used the protein kinase inhibitor H-7 to test further the hypothesis that TPA-induced modulation of bag cell excitability is mediated by activation of PKC. We found that $20 \mathrm{nM}$ TPA significantly enhanced action potential height in 8 of 8 cells that were not incubated in $\mathrm{H}-7$. Addition of $100 \mu \mathrm{M} \mathrm{H}-7$ completely blocked the effect of TPA on bag cell action potentials in 4 out 
A. No H-7

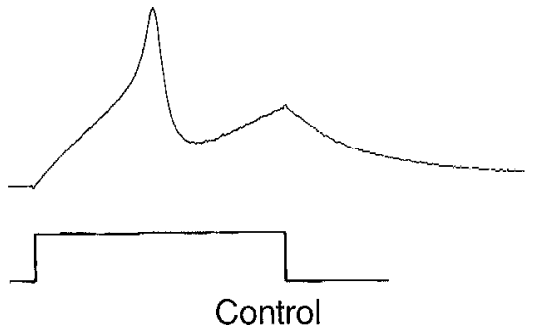

B. $100 \mu \mathrm{M} \mathrm{H}-7$

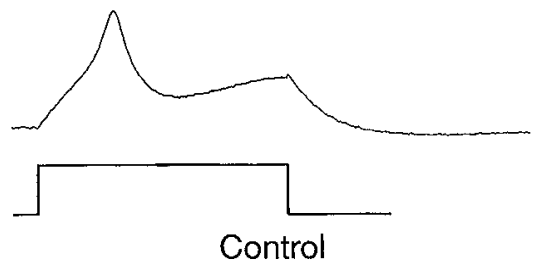

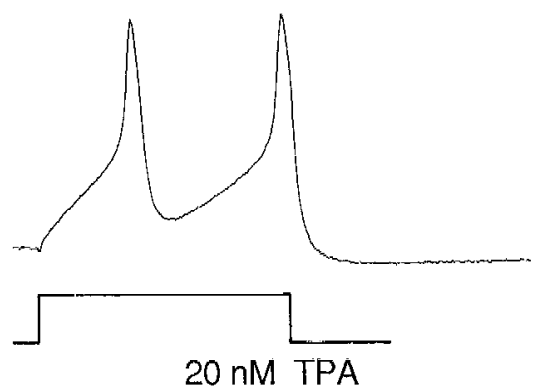

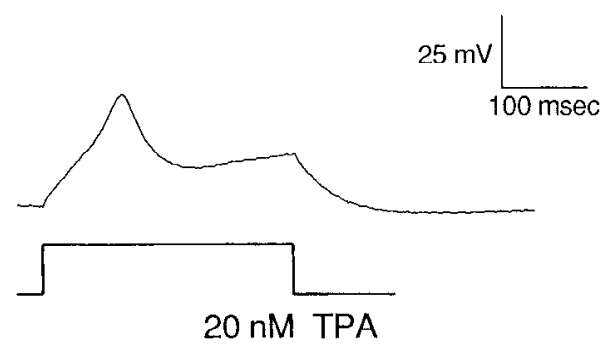

Figure 1. H-7 prevents phorbol esterinduced enhancement of bag cell action potentials. Action potentials were evoked by injection of a constant amount of depolarizing current into control and $\mathrm{H}$-7-treated bag cell neurons before addition of TPA and 30 min after addition of $20 \mathrm{nM}_{\mathrm{M}}$ TPA. These data are representative of 8 control cells and $5 \mathrm{H}$-7-treated cells (from 3 animals). of 5 cells when added at least 15 min before addition of TPA (Fig. 1). Shorter H-7 pretreatments were not examined. In 1 of the 5 cells TPA slightly enhanced the action potential in the presence of $\mathrm{H}-7$. In voltage-clamp experiments using internally dialyzed cells we found that incubation of bag cell neurons with $100 \mu \mathrm{M} \mathrm{H}-7$ for $15 \mathrm{~min}$ prior to the addition of TPA (20 nM) resulted in $60-70 \%$ inhibition of the calcium current enhancing effect of TPA $(p<0.01$; Fig. $2 A)$. However, H-7 had no effect on calcium currents in cells that were not treated with TPA (Fig. $2 B)$.

\section{Effect of $\mathrm{H}-7$ and PKA-I on forskolin or cAMP} analog-induced modulation of bag cell neuronal excitability

The height and width of action potentials in bag cell neurons can also be enhanced by cAMP analogs or the adenylate cyclase activator forskolin when added in combination with a phosphodiesterase inhibitor such as theophylline. Because $\mathrm{H}-7$ inhibits cAMP-PK in cell-free preparations (Hidaka et al., 1984), we tested the effects of $\mathrm{H}-7$ on action potentials in the presence of forskolin and theophylline. After a series of stimulus trains, isolated neurons were treated with $50 \mu \mathrm{M}$ forskolin plus $1 \mathrm{~mm}$ theophylline. Consistent with previous results (Kauer and Kaczmarek, 1985), control uninjected cells, or cells injected with carrier medium alone, responded to forskolin/theophylline with a marked enhancement in the height and width of the action potentials evoked by depolarizing current pulses (Fig. 3). We found that incubation of bag cell neurons with $100 \mu \mathrm{M} \mathrm{H}-7$ for $15 \mathrm{~min}$ prior to addition of forskolin/theophylline had no effect on forskolin/theophylline-induced enhancement of action potentials (Fig. 3). In addition, $\mathrm{H}-7$ did not reverse the enhancement of action potentials in cells pretreated with forskolin/theophylline. cAMP analogs and forskolin/theophylline also enhance action potentials of bag cell neurons in the presence of TEA and this effect on spike width is very much enhanced over that observed in normal extracellular medium. Consistent with the above results, we also found that $100 \mu \mathrm{M} \mathrm{H}-7$ failed to prevent
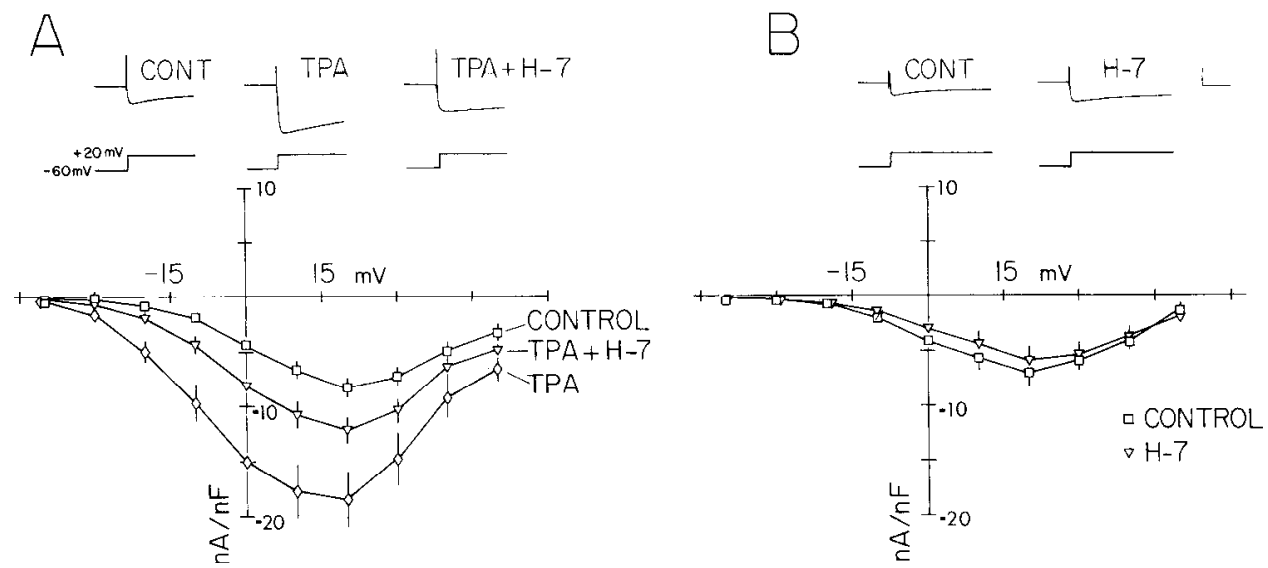

Figure 2. Pretreatment with $\mathrm{H}-7$ prevents TPA-induced increases in calcium currents in bag cell neurons. $A$, Mean ( \pm SEM) $I-V$ (current-voltage) curve (bottom) and representative current traces elicited by stepping from a holding potential of -60 to $+20 \mathrm{mV}$ (top) in control cells, cells treated with $20 \mathrm{nM}$ TPA, and cells treated with 20 nM TPA $15 \mathrm{~min}$ after the addition of $100 \mu \mathrm{M} \mathrm{H}-7$ (8 cells from 2 animals in each group). $B$, Mean ( \pm SEM) $I-V$ curve and representative current traces from control cells and cells treated with 100 $\mu \mathrm{M} \mathrm{H}-7$ in the absence of TPA $(5$ cells from 1 animal in each group). Scale bars, $20 \mathrm{nA}, 25 \mathrm{msec}$. For the $I-V$ curves, peak inward currents were normalized by cell capacitance (estimated by integrating the unfiltered current transient evoked by a brief hyperpolarizing pulse). 


\section{CONTROL}

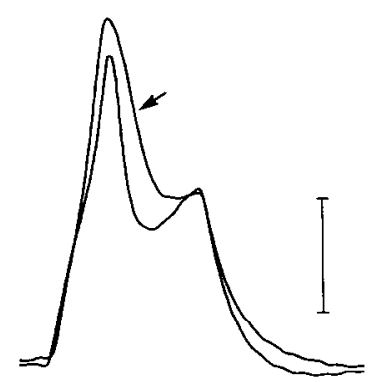

Figure 3. PKA-I, but not H-7, prevents forskolin/theophylline-stimulated enhancement of action potentials. Action potentials were elicited by injection of depolarizing current before and after addition of forskolin/theophylline. Arrows denote traces taken after addition of forskolin/theophylline. Data are shown for a vehicle-injected cell, a cell in which PKA-I was injected prior to addition of forskolin/ theophylline (each representative of 8 cells from 8 animals) and a cell exposed to $100 \mu \mathrm{M} \mathrm{H}-7$ for at least 15 min prior to addition of forskolin/theophylline (representative of 3 cells from 1 animal). Vertical calibration bars, $20 \mathrm{mV}$.

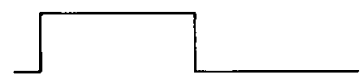

PKA-I INJECTED $\quad 100 \mu \mathrm{M} \mathrm{H}-7$
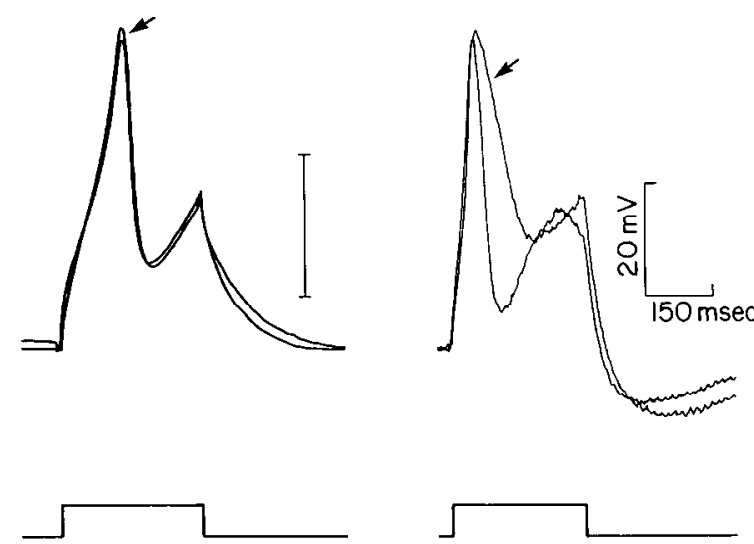

$\sqrt{1}$

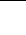

$\operatorname{Ioln} \mathrm{A}$ or reverse the enhancement of action potentials by the cAMP analog adenosine-3':5'-monophosphothioate (Boehringer Mannheim, Indianapolis, IN) in the presence of TEA $(n=3)$.

In contrast to this lack of effect of $\mathrm{H}-7$, we found that the effects of forskolin/theophylline on action potentials could be prevented by intracellular injections of PKA-I. Eight bag cell neurons were injected with PKA-I prior to the addition of forskolin/theophylline. Injection of PKA-I produced a slight narrowing of action potentials in 4 of the cells, while other propcrtics of the cclls (resting potential, input resistance) were unaffected by the injection. No enhancement of action potentials in response to subsequent addition of forskolin/theophylline was, however, detected in any of the 8 PKA-I injected cells (Fig. 3 ). In 5 cases, action potentials continued to diminish after forskolin/theophylline addition. Treatment of uninjected cells with forskolin/theophylline normally produces an increase in input resistance (mean increase $=50.5 \pm 19.9 \%$ for 3 cells in which input resistance was measured with hyperpolarizing current pulses). However, no changes in input resistance (mean change $=-0.03 \pm 3.9 \%, n=3$ ) were observed after forskolin/theophylline treatment of PKA-I injected cells.

In addition to preventing the effects of forskolin/theophylline, PKA-I reversed the changes in the electrical properties of isolated bag cell neurons if injected after the drugs had been applied (Fig. 4). As described previously (Kaczmarek et al., 1980) stimulation at frequencies close to $1 \mathrm{~Hz}$ produces frequency-dependent spike enhancement. A fully enhanced action potential is obtained after about 5 or 6 pulses, after which further stimulation produces little change in shape. In addition to increasing action potential height and width, application of forskolin/theophylline alters the frequency-dependent enhancement such that fully enhanced action potentials are usually obtained by the second pulse (Fig. 4). Figure 4 shows oscilloscope traces of bag cell action potentials in response to a train of depolarizing current pulses before and after exposure of the cells to forskolin/ theophylline and after subsequent pressure injection of PKA-I. Both the height and the width of the action potentials were reduced toward control levels by the injection. This reversal occurred with no change in the resting potential of the cells. Furthermore, the forskolin-induced change in frequency-dependent spike enhancement was reversed. Interestingly, recovery of width was not fully complete (compare $A$ and $C$ in Fig. 4). It is possible that the residual effect on spike width after PKA-I injection is due to a non-cAMP-dependent effect of forskolin (see Discussion). The effect of PKA-I could not be observed with control injections of carrier medium. Although excessive pressure injections of carrier media alone could result in cell damage associated with a loss of action potentials, such nonspecific effects, which have been described previously (Kaczmarek et al., 1980), could be clearly distinguished from the effects of the inhibitor in that they were accompanied by loss of membrane potential and never produced a decrease in the width of evoked action potentials.

\section{Effect of $H-7$ on $C A M P$-induced granule movement}

Forskolin/theophylline induces changes in distribution and transport of organelles in growth cones of bag cell neurons grown in culture (Forscher et al., 1987). In untreated cells, viewed with video-enhanced DIC microscopy, growth cones have fanlike lamellae that contain no microtubules or organelles. Addition of forskolin results in rapid movement of microtubules and organelles into the lamellae such that organelles fill most or all of the lamellae within 15-20 min of forskolin addition. This effect of forskolin is potentiated by phosphodiesterase inhibitors and is mimicked by cAMP analogs. The effect of cAMP analogs or forskolin is reversed within $5-10 \mathrm{~min}$ after these agents are removed from the medium.

We employed the granule movement response to forskolin as another assay with which to assess the effect of $\mathrm{H}-7$ on cAMPdependent processes in intact bag cell neurons. Cells were viewed using video-enhanced DIC microscopy and the percentage of the growth cone area filled with microtubules and organelles was determined in cells before addition of forskolin/theophylline and 15-30 min after addition of forskolin/theophylline (50 $\mu \mathrm{M} / 1 \mathrm{mM})$. The cells were then incubated for $45 \mathrm{~min}$ in $100 \mu \mathrm{M}$ $\mathrm{H}-7$ in the continued presence of forskolin/theophylline and the percent area filled with organelles was determined a third time. $\mathrm{H}-7$ did not reverse the effect of forskolin/theophylline in any of the growth cones examined, indicating that $\mathrm{H}-7$ did not inhibit this cAMP-dependent process (Fig. 5). Since removal of activators of cAMP rapidly reverses the effect of these agents on organelle transport (Forscher et al., 1987), it would be ex- 


\section{A. CONTROL}

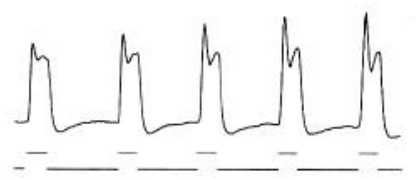

B. CAMP $\uparrow$

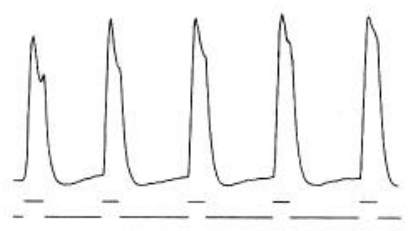

C. CAMP $\uparrow+$ PKA-I

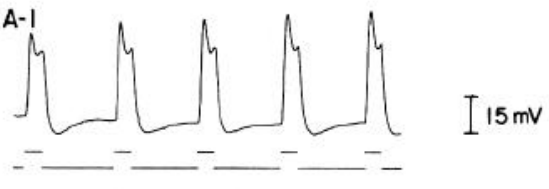

D.

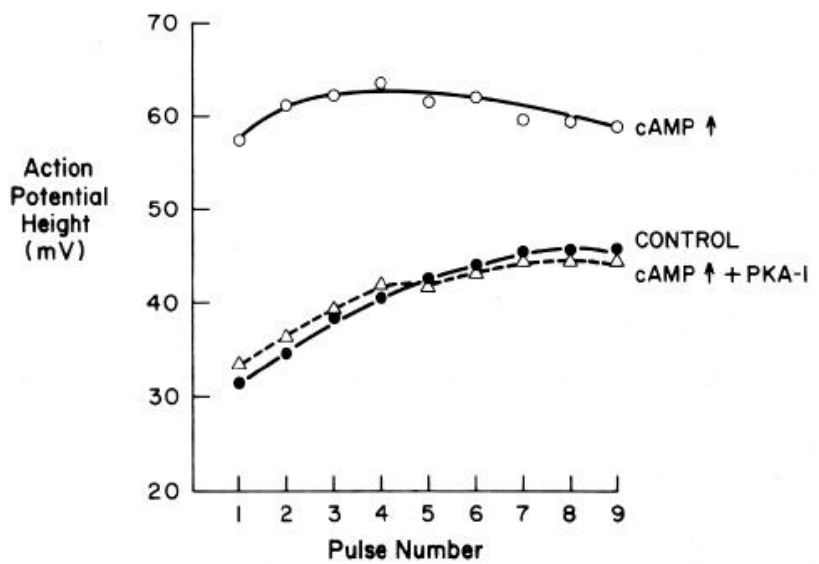

Figure 4. PKA-I injection reverses forskolin/theophylline-induced enhancement of action potentials. Oscilloscope traces of the voltage responses of isolated cultured bag cell neurons (upper traces) to a train of 5 constant current pulses of $200 \mathrm{msec}$ duration are shown. Responses are shown before $(A)$ and $7 \frac{1}{2}$ min after $(B)$ treatment with forskolin/ theophylline $(50 \mu \mathrm{m} / 1 \mathrm{~mm}) . C$. Traces obtained $10 \mathrm{~min}$ after a subsequent pressure injection of PKA-I. $D$, Plot of the height of successive action potentials in a train of 9 stimulus pulses in this cell, before (control), $71 / 2 \mathrm{~min}$ after forskolin/theophylline (cAMP†), and $10 \mathrm{~min}$ after microinjection of PKA-I (cAMP $\uparrow+$ PKA-I). The data shown are representative of 2 cells from 2 animals.

pected that, if cAMP acts through cAMP-PK, inhibition of cAMP-PK should also reverse the effect of cAMP on organelle transport.

\section{Effect of $\mathrm{H}-7$ on forskolin-induced protein phosphorylation}

Incubation of cultured bag cell neurons with ${ }^{32} \mathrm{P}$ orthophosphate results in incorporation of radioactivity into a number of endogenous proteins (Fig. 6). Addition of forskolin/theophylline $(50 \mu \mathrm{M} / 1 \mathrm{mM})$ altered the incorporation of radioactivity into a number of these phosphoproteins. One particularly reliable effect of forskolin/theophylline treatment was to increase incorporation of ${ }^{32} \mathrm{P}_{\mathrm{i}}$ into a $40 \mathrm{kDa}$ protein with a $\mathrm{p} I$ of 4.8 (Fig. 6). We found that forskolin/theophylline-induced changes in protein phosphorylation were unaffected by $\mathrm{H}-7$. In particular, 100 $\mu \mathrm{M} \mathrm{H}-7$ did not alter the effect of forskolin/theophylline (50 $\mu \mathrm{M} /$

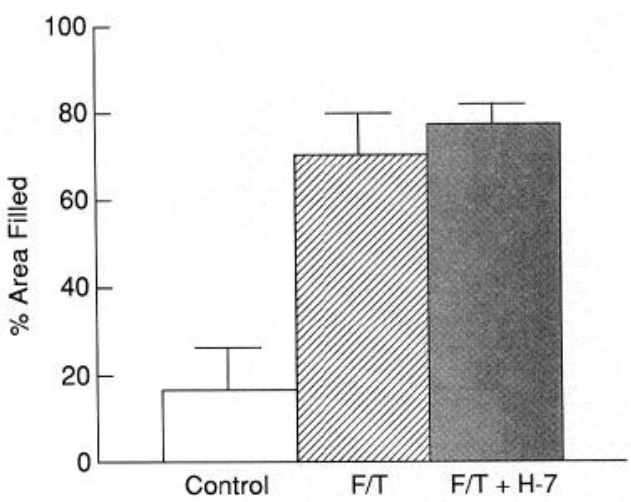

Figure 5. H-7 does not inhibit forskolin/theophylline-induced changes in organelle distribution in growth cones of bag cell neurons. Growth cones were observed with DIC video-enhanced microscopy and the area of the lamellae regions filled with organelles was determined as described by Forscher et al. (1987). Measurements were made in single growth cones prior to addition of any drug and 15-30 min after addition of forskolin/theophylline $(20 \mu \mathrm{M} / 1 \mathrm{mM})$. H-7 $(100 \mu \mathrm{M})$ was then added and a third area measurement was made 45 min after $\mathrm{H}-7$ addition. Data shown are means \pm SEM from 3 cells taken from 3 animals.

$1 \mathrm{~mm}$ ) on the incorporation of ${ }^{32} \mathrm{Pi}$ into the $40 \mathrm{kDa}$ protein. These data suggest that this concentration of $\mathrm{H}-7$ does not inhibit cAMP-induced protein phosphorylation in intact bag cell neurons.

\section{Discussion}

Much evidence suggests that PKC and cAMP-PK play key roles in the long-term changes in excitability of Aplysia bag cell neurons that occur after stimulation of the afferent input to these cells. In the present study, we tested the hypothesis that the effect of phorbol esters on bag cell excitability is mediated by activation of a protein kinase. This was accomplished by measuring the effect of the protein kinase inhibitor H-7 on TPAinduced enhancement of action potentials and calcium currents. We found that $\mathrm{H}-7$ prevents phorbol ester-induced enhancement of action potential height when added to cells at least 15 min prior to addition of TPA. Furthermore, $\mathrm{H}-7$ partially blocks the phorbol ester-induced increase in calcium current when added 15 min prior to TPA addition. In the accompanying paper (Conn et al., 1989), we report that a structurally distinct PKC inhibitor, sphinganine, also inhibits TPA-induced enhancement of action potential height and calcium current in bag cell neurons. These PKC inhibitors have no effect on calcium current in cells that were not treated with TPA, suggesting that $\mathrm{H}-7$ does not inhibit the small-conductance calcium channel. These findings indicate that the effects of phorbol esters in these neurons are likely to be mediated by PKC.

Although H-7 is commonly used as a PKC inhibitor, it also inhibits mammalian cAMP-PK in broken cell preparations. Interestingly, we found that $\mathrm{H}-7$ does not inhibit enhancement of action potentials in bag cell neurons by the adenylate cyclase activator forskolin or a cAMP analog. In contrast, intracellular injection of PKA-I into bag cell neurons prior to addition of forskolin prevented subsequent enhancement of action potentials. Furthermore, if PKA-I is injected into cells that have been pretreated with forskolin, the effects of forskolin are reversed. These results, coupled with the previous report that injection of the purified catalytic subunit of cAMP-PK mimics the effect of forskolin on action potentials, provide evidence that the ma- 


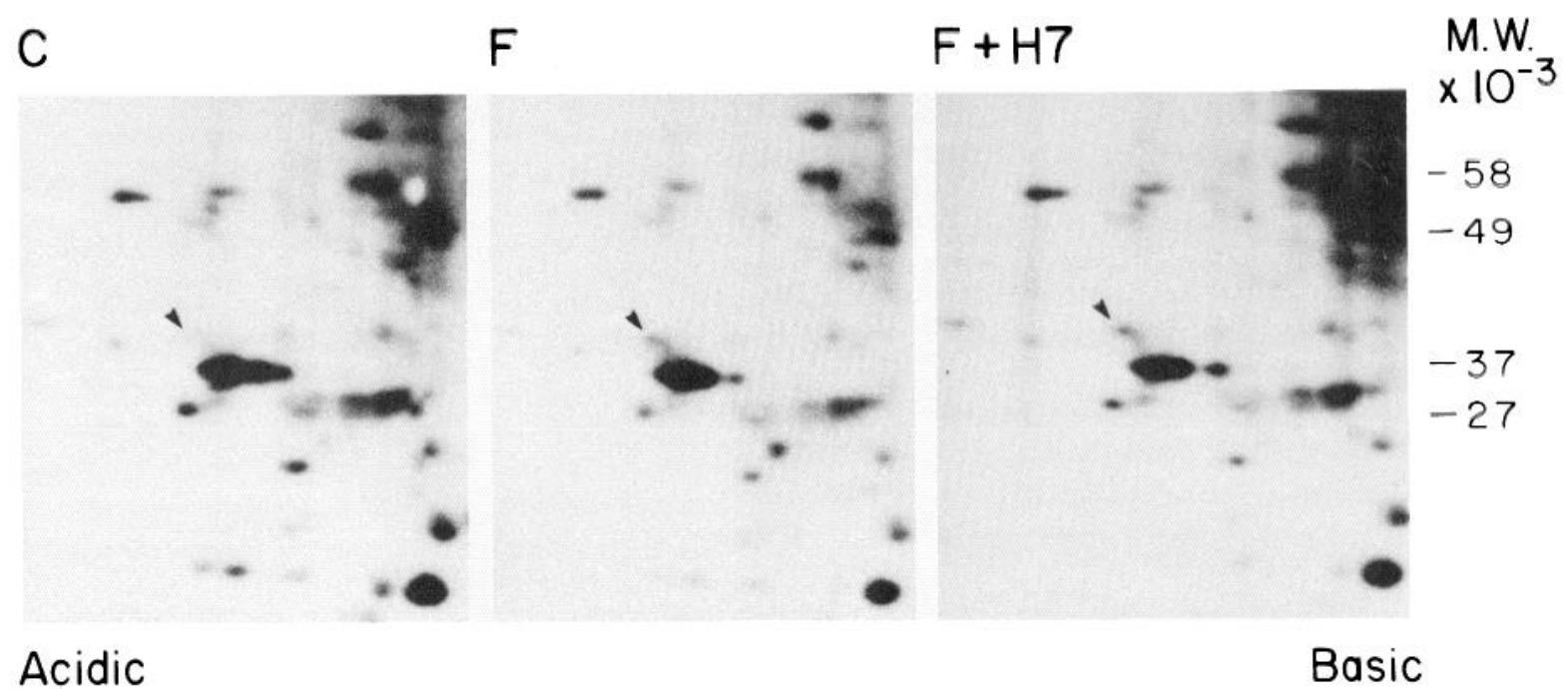

Figure 6. H-7 does not inhibit forskolin/theophylline-induced protein phosphorylation in bag cell neurons. Portions of autoradiograms of dried gels from 2-dimensional PAGE of SDS-soluble bag cell ${ }^{32} \mathrm{Pi}$-labeled proteins are shown. Proteins were extracted from cells incubated in controlcarrier medium $(C)$, forskolin/theophylline $(50 \mu \mathrm{M} / 1 \mathrm{mM})(F)$, or forskolin/theophylline plus $100 \mu \mathrm{M} \mathrm{H}-7(F+H-7)$. The arrows indicate the

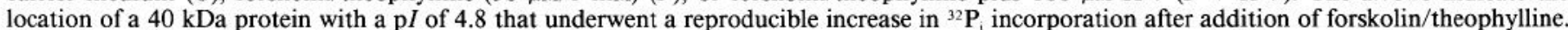
This effect of forskolin/theophylline was seen in 6 out of 6 separate experiments in the absence of $\mathrm{H}-7$ and 3 out of 3 experiments in the presence of $\mathrm{H}-7$. Phosphorylation of the $40 \mathrm{kDa}$ protein was chosen over other protein spots as an index of forskolin/theophylline-induced protein phosphorylation because forskolin/theophylline-induced increases in ${ }^{32} \mathrm{P}$ incorporation into other protein spots (e.g., MW $\left.25 \mathrm{~K}\right)$ were less reliable from experiment to experiment.

jor effect of forskolin on action potentials in these neurons is mediated by activation of cAMP-PK.

Voltage-clamp experiments have shown that forskolin/theophylline decreases the amplitude of voltage-dependent potassium currents in the bag cell neurons (Kaczmarek and Strumwasser, 1984; Strong, 1984; Strong and Kaczmarek, 1986). Recently, the specificity of the action of forskolin has been called into question. It has been reported that both forskolin and 1,9dideoxy-forskolin, a forskolin analog that is inactive on adenylate cyclase, decrease potassium currents in several cell types (Coombs and Thompson, 1987; Hoshi et al., 1988; Lewis and Cahalan, 1988), suggesting that forskolin may inhibit some potassium channels by a mechanism that is not dependent on cAMP. We have also detected a suppressive effect of 1,9-dideoxy-forskolin on potassium currents in dialyzed bag cell neurons (unpublished observations). We have found, however, that the effects of forskolin on delayed potassium currents are partially mimicked by membrane permeant cAMP analogs (Kaczmarek and Strumwasser, 1984) and by a peptide that increases cAMP levels in bag cell neurons (beta bag cell peptide) (Loechner and Kaczmarek, 1987). Furthermore, a peptide that decreases cAMP levels in these cells (alpha bag cell peptide) increases the delayed potassium currents (Loechner and Kaczmarek, 1987) and diminishes the effect of forskolin/theophylline on these currents (Kauer et al., 1987). Thus, it is likely that the effects of forskolin on potassium currents in these cells are at least partially mediated by cAMP. We have not yet examined potassium currents directly in the PKA-I injected cells and cannot therefore rule out the possibility that PKA-I prevents the enhancement of action potentials by a mechanism other than inhibition of the effect of forskolin on the delayed potassium currents. For instance, cAMP analogs have been shown to induce a region of negative slope resistance in the steady-state current voltage relations (Kaczmarek and Strumwasser, 1984), suggesting that as yet uncharacterized conductances may also be influenced by cAMP.
We also investigated the effect of $\mathrm{H}-7$ on other cAMP-induced responses to determine if $\mathrm{H}-7$ is selective for PKC relative to cAMP-PK in intact bag cell neurons. H-7 did not inhibit forskolin-induced protein phosphorylation in cultured bag cell neurons or forskolin-induced changes in organelle movement in growth cones of bag cell neurons. These data strongly suggest that $\mathrm{H}-7$ is selective for PKC relative to cAMP-PK in intact bag cell neurons at the concentration used in this study. Consistent with this conclusion, we have also found that $\mathrm{H}-7$ does not inhibit 5-HT-induced modulation of bursting in Aplysia neuron R15 or forskolin-induced secretion of ACTH from AtT20 cells (P. J. Conn, J. A. Strong, and L. K. Kaczmarek, unpublished observations). Both of these effects have been shown to depend on elevation of cAMP and to be blocked by PKA-I (Adams and Levitan, 1982; Reisine et al., 1985), suggesting that, as in the bag cell neurons, H-7 does not inhibit cAMP-PK in these cells. However, caution should be taken in extrapolating the selectivity of $\mathrm{H}-7$ demonstrated here to other cell types.

When characterized in vitro, $\mathrm{H}-7$ has nearly equal potency as an inhibitor of PKC and CAMP-PK in their soluble forms. Hidaka et al. (1984) characterized the effect of H-7 on these enzymes in vitro and found that the inhibitory action of $\mathrm{H}-7$ on both cAMP-PK and PKC is mediated by competition with ATP. The $K_{i}$ value of H-7 and the $K_{m}$ value of ATP for both enzymes are about $5 \mu \mathrm{M}$ (Hidaka et al., 1984). Whole-cell ATP concentrations are in the range of 1-5 mM. Thus, based on the in vitro studies, one would predict that submillimolar concentrations of H-7 could not effectively inhibit either enzyme in intact cells. However, it has been observed empirically that $\mathrm{H}-7$ does inhibit PKC-mediated responses in a number of cell types (Inagaki et al., 1984; Kawamoto et al., 1984; Fujita et al., 1986; Nishikawa et al., 1986; Shibanamu et al., 1987; Figs. 1, 2). Differences in kinetic properties and sensitivity of enzymes to inhibitors have been observed in a number of cases when comparisons were made between the behavior of an enzyme in broken cell preparations and in its native environment (Youdim and Woods, 
1975). Possibly, in intact cells, $\mathrm{H}-7$ inhibits PKC by a mechanism other than competition with ATP.

In conclusion, we have found that $\mathrm{H}-7$ inhibits the effects of phorbol esters on action potentials and calcium current and that PKA-I inhibits the effect of forskolin on action potentials in Aplysia bag cell neurons, supporting the hypothesis that these effects are mediated by PKC and cAMP-PK, respectively. Furthermore, we have found that $\mathrm{H}-7$ is selective for $\mathrm{PKC}$ relative to cAMP-PK in intact Aplysia neurons. This finding, along with the previous reports that $\mathrm{H}-7$ is selective for $\mathrm{PKC}$ relative to $\mathrm{Ca} / \mathrm{CaM}-\mathrm{PK}$ in intact cells, suggests that $\mathrm{H}-7$ may prove to be a useful tool for probing PKC-mediated changes in such cells.

\section{References}

Adams, W. B., and I. B. Levitan (1982) Intracellular injection of protein kinase inhibitor blocks the serotonin-induced increase in $\mathrm{K}^{+}$ conductance in Aplysia neuron R15. Proc. Natl. Acad. Sci. USA 79: 3877-3880.

Ashby, C. D., and D. A. Walsh (1972) Characterization of the interaction of a protein inhibitor with adenosine $3^{\prime}, 5^{\prime}$-monophosphate dependent protein kinases. J. Biol. Chem. 247: 6637-6642.

Castellucci, V. F., A. Nairn, P. Greengard, J. H. Schwartz, and E. R. Kandel (1982) Inhibition of adenosine 3':5'-monophosphate-dependent protein kinase blocks presynaptic facilitation in Aplysia. $\mathbf{J}$. Neurosci. 2: 1673-1681.

Conn, P. J., J. A. Strong, and L. K. Kaczmarek (1987) Protein kinase $\mathrm{C}$ inhibitors prevent phorbol ester-induced increases in calcium currents in Aplysia bag cell neurons. Soc. Neurosci. Abstr. 13: 106.

Conn, P. J., J. A. Strong, and L. K. Kaczmarek (1988) Activity of protein kinase $C(\mathrm{PKC})$-induced calcium channel persists after inactivation of the enzyme. Soc. Neurosci. Abstr. 14: 153.

Conn, P. J., J. A. Strong, and L. K. Kaczmarek (1989) Inhibitors of protein kinase $\mathrm{C}$ prevent enhancement of calcium current and action potentials in peptidergic neurons of Aplysia. J. Neurosci. 9: 480-487.

Coombs, J., and S. Thompson (1987) Forskolin's effect on transient $\mathrm{K}$ current in nudibranch neurons is not reproduced by cAMP. $J$. Neurosci. 7: 443-452.

DeReimer, S. A., J. A. Strong, K. A. Albert, P. Greengard, and L. K. Kaczmarek (1985) Enhancement of calcium current in Aplysia neurons by phorbol ester and protein kinase C. Nature 313: 313-316.

Forscher, P., L. K. Kaczmarek, J. Buchanan, and S. J. Smith (1987) Cyclic AMP induces changes in distribution and transport of organelles within growth cones of Aplysia bag cell neurons. J. Neurosci. 7: $3600-3611$.

Fujita, I., K. Takeshige, and S. Minakami (1986) Inhibition of neutrophil superoxide formation by 1-(5-isoquinolinesulfonyl)-2-methylpiperazine (H-7), an inhibitor of protein kinase-C. Biochem. Pharmacol. 35: 4555-4562.

Hamill, O. P., A. Marty, E. Neher, B. Sakman, and F. J. Sigworth (1981) Improved patch-clamp techniques for high-resolution current recording from cells and cell-free membrane patches. Pfluegers Arch. 391: 85-100.

Hidaka, H., M. Inagaki, S. Kawamoto, and Y. Sasaki (1984) Isoquinolinesulfonamides, novel and potent inhibitors of cyclic nucleotidedependent protein kinase and protein kinase C. Biochemistry 23: 5036-5041.

Hoshi, T., S. S. Garber, and R. W. Aldrich (1988) Effect of forskolin on voltage-gated $\mathrm{K}^{+}$channels is independent of adenylate cyclase activation. Science 240: 1652-1655.

Inagaki, M., S. Kawamoto, and H. Hidaka (1984) Serotonin secretion from human platelets may be modified by $\mathrm{Ca}^{++}$-activated, phospholipid-dependent myosin phosphorylation. J. Biol. Chen. 259: 1432114323.

Kaczmarek, L. K., and F. Strumwasser (1981) The expression of longlasting afterdischarge by isolated Aplysia bag cell neurons. J. Neurosci. 1: 626-634.
Kaczmarek, L. K., and F. Strumwasser (1984) A voltage clamp analysis of currents underlying cAMP-induced membrane modulation in isolated peptidergic neurons of Aplysia. J. Neurophysiol. 52: 340349.

Kaczmarek, L. K., K. R. Jennings, F. Strumwasser, A. C. Nairn, U. Walter, F. D. Wilson, and P. Greengard (1980) Microinjection of catalytic subunit of cyclic AMP-dependent protein kinase enhances calcium action potentials of bag cell neurons in cell culture. Proc. Natl. Acad. Sci. USA 77: 7487-7491.

Kaczmarek, L. K., A. C. Nairn, and P. Greengard (1984) Microinjection of protein kinase inhibitor prevents enhancement of action potentials in peptidergic neurons of Aplysia. Soc. Neurosci. Abstr. 10: 895.

Kaczmarek, L. K., J. A. Strong, and J. A. Kauer (1986) The role of protein kinases in the control of prolonged changes in neuronal excitability. Prog. Brain Res. 69: 77-90.

Kaner, J. A., and L. K. Kaczmarek (1985) Peptidergic neurons of Aplysia lose their response to cyclic adenosine $3^{\prime}: 5^{\prime}$-monophosphate during a prolonged refractory period. J. Neurosci. 5: 1399-1345.

Kauer, J. A., T. E. Fisher, and L. K. Kaczmarek (1987) Alpha bag cell peptide directly modulates the excitability of the neurons that release it. J. Neurosci. 7: 3623-3632.

Kawamoto, S., and H. Hidaka (1984) 1-(5-isoquinolinesulfonyl)-2methylpiperazine (H-7) is a selective inhibitor of protein kinase $\mathrm{C}$ in rabbit platelets. Biochem. Biophys. Res. Commun. 125: 258-264.

Leibovitz, A. (1963) The growth and maintenance of tissue-cell cultures in free gas exchange with the atmosphere. Am. J. Hyg. 78: 173180

Lewis, R. S., and M. D. Cahalan (1988) The plasticity of ion channels: Parallels between the nervous and immune systems. Trends Neurosci. 11: $214-218$

Loechner, K. J., and L. K. Kaczmarek (1987) Regulation of isolated bag cell neurons of Aplysia by alpha-, beta-, and gamma-bag cell peptides. Soc. Neurosci. Abstr. 13: 1071.

Nestler, E. J., and P. Greengard (1984) Protein Phosphorylation in the Nervous System, Wiley, New York.

Nishikawa, M., Y. Uemura, H. Hidaka, and S. Shirakawa (1986) 1-(5-isoquinolinesulfonyl)-2-methylpiperazine (H-7), a potent inhibitor of protein kinases, inhibits the differentiation of HL-60 cells induced by phorbol diester. Life Sci. 39: 1101-1 107.

O'Farrell, P. H. (1975) High resolution two-dimensional electrophoresis of proteins. J. Biol. Chem. 250: 4007-4021.

Reisine, T., G. Rougon, J. Barbet, and H.-U. Affolter (1985) Corticotropin-releasing factor-induced adrenocorticotropin hormone release and synthesis is blocked by incorporation of the inhibitor of cycle AMP-dependent protein kinase into anterior pituitary tumor cells by liposomes. Proc. Natl. Acad. Sci. USA 82: 8261-8265.

Shibanuma, M., T. Kuroki, and K. Nose (1978) Effects of the protein kinase $\mathrm{C}$ inhibitor $\mathrm{H}-7$ and calmodulin antagonist $\mathrm{W}-7$ on superoxide production in growing and resting human histiocytic leukemia cells (U937). Biochem. Biophys. Res. Commun. 1444: 1317-1323.

Strong, J. A. (1984) Modulation of potassium current kinetics in bag cell neurons of Aplysia by an activator of adenylate cyclase. J. Neurosci. 4: $2772-2783$.

Strong, J. A., and L. K. Kaczmarek (1986) Multiple components of delayed potassium current in peptidergic neurons of Aplysia: Modulation by an activator of adenylate cyclase. J. Neurosci. 6:814-822.

Strong, J. A., and L. K. Kaczmarek (1987) Potassium currents that regulate action potentials and repetitive firing. In Neuromodulation, L. K. Kaczmarek and I. B. Levitan, eds., pp. 119-137, Oxford U. P., New York.

Strong, J. A., A. P. Fox, R. W. Tsien, and L. K. Kaczmarek (1987) Stimulation of protein kinase $\mathrm{C}$ recruits covert calcium channels in Aplysia bag cell neurons. Nature 325: 714-717.

Youdim, M. B. H., and H. F. Woods (1975) The influence of environment on the rates of metabolic processes and the properties of enzymes. Biochem. Pharmacol. 24: 317-323. 